\title{
Identification of differentially expressed genes response to TCDD in rat brain after long-term low-dose exposure
}

\author{
Yangsheng Chen ${ }^{1,2, * *}$, Li Xu ${ }^{1,2, * *}$, Heidi Q.H. Xie ${ }^{1,2, *}$, Tuan $\mathrm{Xu}^{1,2}$, Hualing $\mathrm{Fu}^{1,2}$, \\ Songyan Zhang ${ }^{1,2}$, Rui Sha ${ }^{1,2}$, Yingjie Xia ${ }^{1,2}$, Bin Zhao ${ }^{1,2, *}$
}

1. State Key Laboratory of Environmental Chemistry and Ecotoxicology, Research Center for Eco-Environmental Sciences, Chinese Academy of Sciences, Beijing 100085, China

2. University of Chinese Academy of Sciences, Beijing 100049, China

\section{A R T I C L E I N F O}

Article history:

Received 31 March 2017

Revised 9 July 2017

Accepted 11 July 2017

Available online 19 July 2017

\section{Keywords:}

TCDD

Long-term exposure

Neurotoxicity

Microarray

Neuroinflammation

\begin{abstract}
A B S T R A C T
Several cohort studies have reported that dioxin and dioxin-like polychlorinated biphenyls might impair the nervous system and lead to neurological or neurodegenerative diseases in the elder people, but there is limited research on the involved mechanism. By using microarray analysis, we figured out the differentially expressed genes between brain samples from SD rats after low-dose $(0.1 \mu \mathrm{g} /(\mathrm{kg} \cdot \mathrm{bw}))$ dioxin exposure for six months and controls. To investigate the function changes in the course of dioxin exposure, Gene Ontology (GO) annotation and Kyoto Encyclopedia of Genes and Genomes (KEGG) pathway analysis were performed on the differentially expressed genes. And the changes of several picked genes have been verified by real-time PCR. A total of 145 up-regulated and 64 down-regulated genes were identified. The metabolic processes, interleukin-1 secretion and production were significantly associated with the differentially expressed genes. And the genes regulated by dioxin also clustered to cholinergic synapse and long-term potentiation. Candidate biomarker genes such as egr1, gad2, gabrb3, abca1, ccr5 and pycard may be toxicological targets for dioxin. Furthermore, synaptic plasticity and neuro-immune system may be two principal affected areas by dioxin.

(C) 2017 The Research Center for Eco-Environmental Sciences, Chinese Academy of Sciences.
\end{abstract} Published by Elsevier B.V.

\section{Introduction}

Dioxin represents a group of persistent organic pollutants which exerts threats on human health. Recently, many studies focused on the neuronal effects of dioxin. The cohort studies focusing on the neurotoxicity of dioxin could be classified into two categories based on the age of people in the cohorts. One major category aiming at children after perinatal dioxin exposure, demonstrated that dioxin might disrupt regular neuronal development and lead to cognitive deficiency. The results of cohort studies have been verified by animal experiments (Kakeyama et al., 2014), and several researches also tried to demonstrate the mechanism involved in the neurotoxicity of dioxin on the neurodevelopment by both animal behavior tests and molecular experiments (Mitsuhashi et al., 2010; Nayyar et al., 2002; Nguyen et al., 2013; Williamson et al., 2005).

But to the other category, in which the cohorts concerned about the effects of dioxin on the nervous system of elder people, there is limited relevant research on the mechanisms. A study to evaluate the consequences of severe occupational intoxication with 2,3,7,8-tetrachlorodibenzo-p-dioxin (TCDD) that occurred during production of the herbicide trichlorophenoxyacetic acid

\footnotetext{
* Corresponding authors. E-mails: qhxie@rcees.ac.cn (Heidi Q.H. Xie), binzhao@rcees.ac.cn (Bin Zhao).

** The authors contributed equally to this work.
} 
in the period 1965-1968, indicated that even forty years past, the blood level of TCDD was still 100 times in the intoxication people higher than in the general population, and a high percent of subjects suffered from neurological and vascular disorders (Pelclova et al., 2009). Another study carried out in 2014 also suggested that dioxin exposure several decades earlier might increase morbidity from Alzheimer disease and peripheral polyneuropathies (Yi et al., 2014). Generally, dietary exposure is the main way for dioxin to enter human body, especially for the majority population. It has been reported that the elder Michigan residents who consume amount of fish from the Great Lakes, get impairments in memory and learning due to the dioxin-like Polychlorinated bipheny (PCB) intake from the fish (Schantz et al., 2001). Even in the developed countries like the U.S, older individuals suffer from high body burden, and their cognitive score was significantly affected by serum concentration of dioxin-like PCB (Bouchard et al., 1999). These results suggest that exposure levels were higher in the past, resulting in older individuals perhaps having high dioxin body burden compared to younger people. In addition, the lower compensation capacity might lead the aging nervous system more vulnerable to neurotoxicant insults (Weiss, 2000). However, there are limited data on possible mechanism involved in the neurotoxic effects of dioxin in the aging nervous system. Recently, researchers are keeping on finding target genes of dioxin on nervous system. For example, the suppression of dioxin on the AChE activity is a new explanation for the neuronal defects induced by dioxin (Xie et al., 2013). Finding out more target genes is necessary for the further investigation of the neurotoxicity of dioxin.

In the present study, to screen differentially expression gene in response to dioxin toxicity in the brain, complementary deoxyribonucleic acid (cRNA) microarray analysis was applied to investigate a global view of molecular changes associated with the mechanisms underlying toxicity following dioxin exposure. The neurotoxicity of dioxin leading to multiple types of neurological disorder in aging brain, might be resulted by interaction of various types of cells and through complex processes. So we investigate the whole brain to obtain gene altered by dioxin and predict possible biological processes and signal pathways affected by dioxin.

\section{Methods and materials}

\subsection{Animals and TCDD exposure}

Twenty-four male Sprague-Dawley (SD) rats were purchased from Vital River Laboratories (VRL; Beijing, China) and housed in the Institute of Psychology (CAS) under specific pathogen-free conditions, at a controlled temperature of $(24 \pm 2)^{\circ} \mathrm{C}$ and humidity of $50 \% \pm 10 \%$, with a cycle of $12 \mathrm{hr}$ light and $12 \mathrm{hr}$ dark. Animals were provided with pellet foods and water ad libitum, and randomly assigned into two groups, TCDD-treated groups and one vehicle control (Rat received Dimethyl sulfoxide (DMSO) diluted in olive oil served as the control). TCDD (Toronto Research Chemicals Inc., Canada) was dissolved in DMSO (Sigma-Aldrich, St. Louis, USA) at stock concentration of $0.01 \mu \mathrm{g} / \mu \mathrm{L}$, and then diluted 1000 times in olive oil as dosing solutions. The rat in TCDD-treated groups was administered with TCDD diluted in olive oil at $0.1 \mu \mathrm{g} / \mathrm{kg}$ of body weight (bw) by gavage every other week. Dose used in the current study was based on previous TCDD chronic exposure reports (Bell et al., 2007; Chen et al., 2009). After 24 weeks of exposure, brain tissue was dissected and stored in $-80^{\circ} \mathrm{C}$ for further studies. All animal experiments were conducted in accordance with animal protocols approved by the Animal Care and Use Committee of Institute of Psychology (CAS).

\subsection{Ribonucleic acid (RNA) isolation, quality control and microarray analysis}

Rat brain tissue was thoroughly grinded in liquid nitrogen. Total RNA of rat brain tissue was isolated using the Thermo Scientific GeneJET RNA Purification Kit (Thermo) and genomic Deoxyribonucleic acid (DNA) was removal by RapidOut DNA Removal Kit following the manufacturer's instructions. One microliter total RNA aliquots were used for quality control by agarose gel electrophoresis and quantified by Nanodrop 2000. All RNA samples used in this study showed no sign of degradation and the ratio of $A_{260} / A_{280}$ reached to 2.0 .

Preparation of cDNA, complementary ribonucleic acid (cRNA), hybridization and scanning of microarrays was performed following manufacturer's protocol. cDNA and biotinylated cRNAs were synthesized from $5 \mu \mathrm{g}$ RNA samples with the Genechip expression 3' amplification reagents (one-cycle cDNA synthesis, and IVT labeling) kits of Affymetrix, and biotinylated probes were hybridized to an Affymetrix Rat Genome 2302.0 array. Microarrays were washed and scanned in an Affymetrix GeneChip Scanner 3000, and the comparison of gene expression profiles between the control and treated samples was performed by using a standard significance analysis of microarray software (Affymetrix Microarray Suite 5.0).

\subsection{Gene Ontology (GO) and pathway enrichment analysis}

Genes showing differential expression were functionally classified based on the GO database using the Database for Annotation, Visualization and Integrated Discovery rate (DAVID) tool (Huang et al., 2009). The significantly altered GO functions with a false discovery rate $(F D R)<0.05$ were identified.

To identify the pathways significantly associated with the genes of interest, the potentially altered pathways with a $p$-value $<0.05$ were predicted using Kyoto Encyclopedia of Genes and Genomes (KEGG) Orthology-Based Annotation System (KOBAS) based on the cumulative hypergeometric distribution algorithm (Wu et al., 2006).

\subsection{Quantitative RT-PCR}

Real-time quantitative real-time polymerase chain reaction (RT-PCR) was used to confirm the differential expression of several dioxin-responsive genes detected in the microarray analysis. First strand complementary cDNA synthesis was performed on $2 \mu \mathrm{g}$ RNA (RevertAid First Strand cDNA Synthesis Kit, Thermo), previously treated with DNase (Rapidout DNA Removal Kit, Thermo). Two microliters of diluted cDNA (1:50) was subjected to PCR cycles by using the GoTaq qPCR Master Mix (Promega). The reaction was incubated at $95^{\circ} \mathrm{C}$ for $2 \mathrm{~min}$, and then followed by 40 cycles of amplification 
(denaturation at $95^{\circ} \mathrm{C}$ for $15 \mathrm{sec}$, annealing at $60^{\circ} \mathrm{C}$ for $20 \mathrm{sec}$ and extension at $72^{\circ} \mathrm{C}$ for $20 \mathrm{sec}$ ).

Assays were performed by using QuantStudionTM 6 Flex Real-Time PCR System (instrument and software) from ThermoFisher. All samples were run in triplicate, and results were analyzed by the $C_{T}$ method. The following primers (forward and reverse) were designed by Primer Premier 6 from sequences obtained from Genebank, and synthesized by Sangon.

Results were normalized to the expression levels of the glyceraldehyde-3-phosphate dehydrogenase (GAPDH) gene. The primers were as follows:

ABCa1: 5'-GGTAGTGTGGCCACTTTCGT-3'

5'-TCTGGGCCTGATGAAAAATC-3' (NM_178095.2 GI:31342527); C4A: 5'-CTGGCTCTGGAGAGTGGAACCT-3'

5'-GCGAGTTGGCTTGGCTACACA-3' (NM_031504.3 GI:2590135 49);

CCR5: 5'-ACCTGCTCTTCCTGCTCACACT-3'

5'-CAAACACAGCCACCACCCAAGT-3' (NM_053960.3 GI:82617 607);

PYCARD: 5'-ACCAACACAGGCAAGCACTCA-3'

5'-TGTTCCAGGTCTGTCACCAAGT-3'(NM_172322.1GI:272292 93);

ERG1: 5'-GCCTCTCCCACATCCGACTTTG-3

5'-CCTTCTTGAGACGCAGCCTTGA-3' (NM_012551.2);

GAD2: 5'-TTCTCCTGGTGGTGCCATCTCC-3'

5'-ATCACGCTGTCTGTTCCGATCC-3' (NM_012563.1 GI:69788 70);

GABRB3: 5'-AACCGCATGATCCGCCTCCA-3' 5'-TTCCACGCCAGTAACAGCCTTG-3' (NM_017065.1 GI:83933 89);

CDKN1a: 5'-CTGCCTGGTTCCTTGCCACTTC-3'

5'-GCTCTGGACGGTACGCTTAGGT-3' (NM_080782.3 GI:736638 97);

GAPDH: 5'-AGTTCAACGGCACAGTCAAG-3'

5'-TACTCAGCACCAGCATCACC-3' (NM_017008.4 GI:4026917 27).

\subsection{Statistical analysis and other assays}

Statistical analyses were performed using the student t-test. Statistically significant changes were classed as $\left.{ }^{*}\right]$ where $\left.p<0.05 ;{ }^{* *}\right]$ where $p<0.01$.

\section{Results}

2.1. Identification of differentially expressed gene profiling in rat brain tissue exposed to TCDD

In present study, we investigate the differentially expressed genes from SD rat brain tissue after TCDD exposure, microarray analysis was performed and results selectively compared with gene expression of tissue exposed to DMSO. From the microarray results, a total of 209 genes were regulated by TCDD. Among them, 145 genes were up-regulated, whereas 64 genes were down-regulated (Table 1). The heat map for the hierarchical clustering of gene expression is shown in Fig. 1, which illustrated distinct
Table 1 - Top 20 of the up- and down-regulated differently expressed genes.

\begin{tabular}{|c|c|c|c|}
\hline GeneCard & RefSeq & Fold change & $p$-Value \\
\hline Pxmp4 & NM_172223 & 13.33925343 & 0.00912467 \\
\hline Jund & NM_138875 & 10.83124828 & 0.011121141 \\
\hline Cdkn1a & NM_080782 & 5.962636471 & 3.29432E-05 \\
\hline Atrx & NM_001105757 & 2.900962 & 0.00529957 \\
\hline LOC100362458 & XM_003750735 & 2.891571045 & 0.039231174 \\
\hline LOC100910231 & NM_001100991 & 2.886780262 & 0.003797469 \\
\hline Falz & NM_001127535 & 2.722794056 & 0.020295363 \\
\hline Klhl42 & NM_001109257 & 2.707603931 & 0.026048815 \\
\hline Pbrm1 & XM_001059164 & 2.67805481 & 0.04198477 \\
\hline Ash1l & NM_001107689 & 2.664185286 & 0.016403424 \\
\hline Adipor2 & NM_001037979 & 2.651825 & 0.002007092 \\
\hline Lsm14b & XM_002729258 & 2.62382 & 0.038684405 \\
\hline Tacr3 & NM_017053 & 2.606 & 553913 \\
\hline Prdm2 & NM_001077648 & 2.59415 & 0.001629744 \\
\hline Tpr & NM_001107185 & 2.536868095 & 0.045589872 \\
\hline Gad2 & NM_012563 & 2.532438993 & 0.034912433 \\
\hline Dnal1 & NM_001109477 & 2.48727107 & 0.039994929 \\
\hline Rab3a & NM_013018 & 2.423046589 & 0.012439184 \\
\hline Cdkn1b & NM_031762 & 2.403 & 0.009301459 \\
\hline Kcnip3 & NM_032462 & 2.400 & 0.021859651 \\
\hline Elk3 & NM_001108743 & -1.732736945 & 0.005505947 \\
\hline LOC1001 & NM_001111269 & -1.717784524 & 0.047877073 \\
\hline Ccr5 & NM_053960 & -1.71 & 5E-05 \\
\hline Pth1r & NM_O2 & -1.6 & 5103 \\
\hline Timm10b & NM_053371 & -1.68 & 51595 \\
\hline Dbp & NM_012543 & -1.68 & 45331 \\
\hline Lap3 & NM_001011910 & -1.672949076 & 0.003002648 \\
\hline Ropn1l & NM_001191086 & -1.670307755 & 0.010397622 \\
\hline Rasgrp3 & NM_001108009 & -1.669539213 & 0.013296276 \\
\hline Egfl6 & NM_001108254 & -1.667181849 & 0.044094641 \\
\hline Tnnt1 & NM_0012772 & -1.66 & 20994 \\
\hline LOC100134871 & NM_001111269 & -1.65 & 0.031533737 \\
\hline Adamts1 & NM_024400 & -1.645494461 & 0.001057997 \\
\hline Abcg314 & NM_001037205 & -1.624035954 & 0.000529547 \\
\hline Leprel4 & NM_021581 & -1.616625547 & 0.015129814 \\
\hline Prom1 & NM_001110137 & -1.612719059 & 0.024797533 \\
\hline Tmem63a & NM_001134496 & -1.601975918 & 0.016769065 \\
\hline Nckap1l & NM_001108119 & -1.599487185 & 0.024088066 \\
\hline LOC100909757 & XR_145741 & -1.59705615 & 0.019917095 \\
\hline Plek & NM_001025750 & -1.588742971 & 0.01286712 \\
\hline
\end{tabular}

gene expression profiles between TCDD exposure sample and DMSO controls.

\subsection{Verification of the differentially expressed genes}

The real-time PCR experiment was performed the verify some of the differentially expressed genes from the microarray results. Results demonstrated that the TCDD induced changes in the expression of ABCa1, C4A, CCR5, PYCARD, CDKN1a, GAD, GABRB3 and ERG1, closely correlated with the corresponding microarray data, although the exact fold change differed between the two assays (Fig. 2). Among these up-regulated genes, the change of ERG1 was most promising (2.40 fond compared with the control group), while CDKN1a and GAD2 were also up-regulated to more than 2 folds $(2.15$ and 2.10 folds, respectively). ABCa1, C4A, CCR5 and PYCARD are down-regulated more than $25 \%$. 


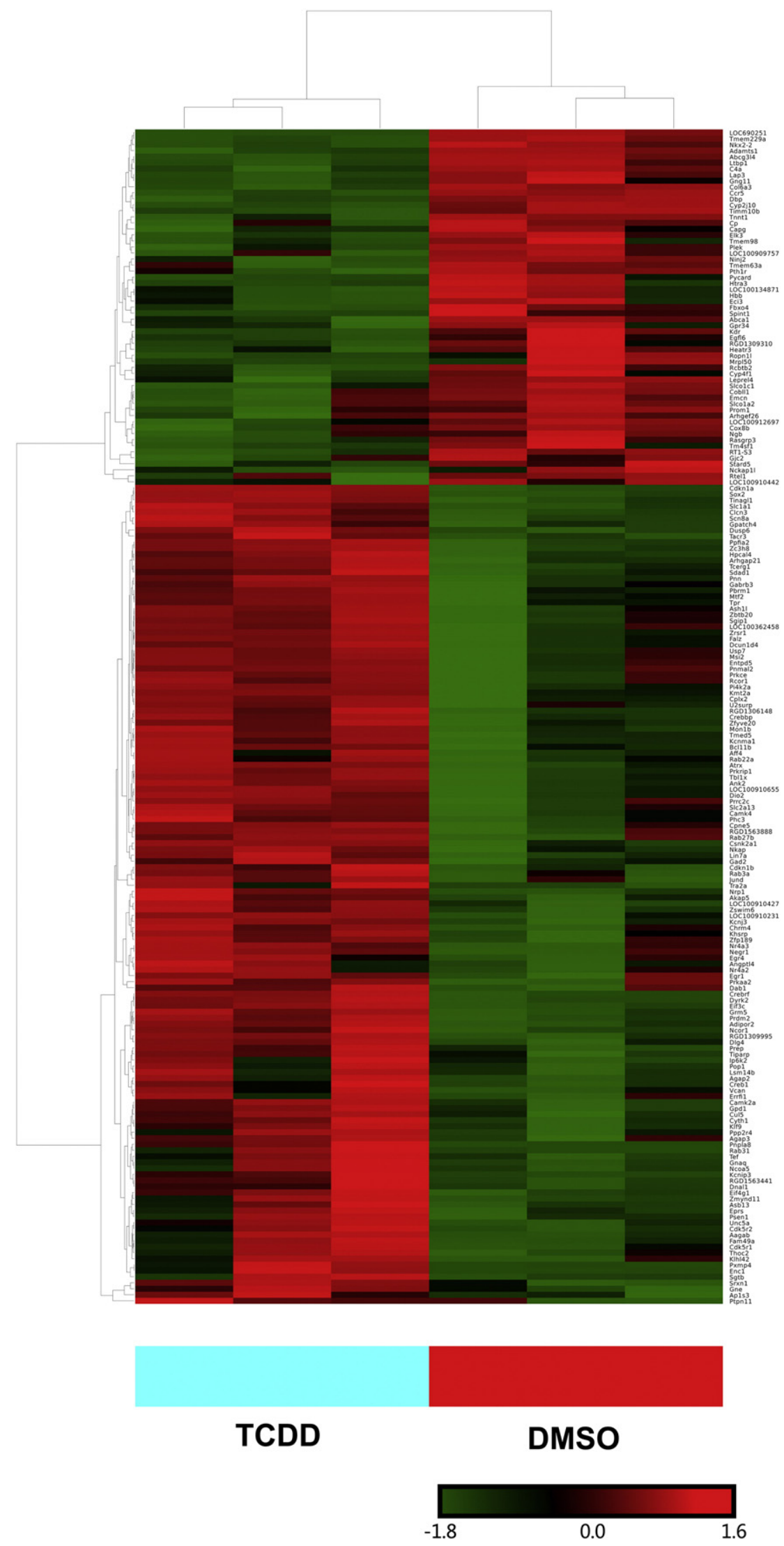

Fig. 1 - A heat map for the hierarchical clustering of gene expression. The results of 3 parallel samples from TCDD (left panel) and Dimethyl Sulphoxide (DMSO) groups (right panel) are shown in the heat map. Red and green bars show up- and down-regulations, respectively. The names of the differently expressed genes are shown at the right side. TCDD: tetrachlorodibenzo-p-dioxin. 
A

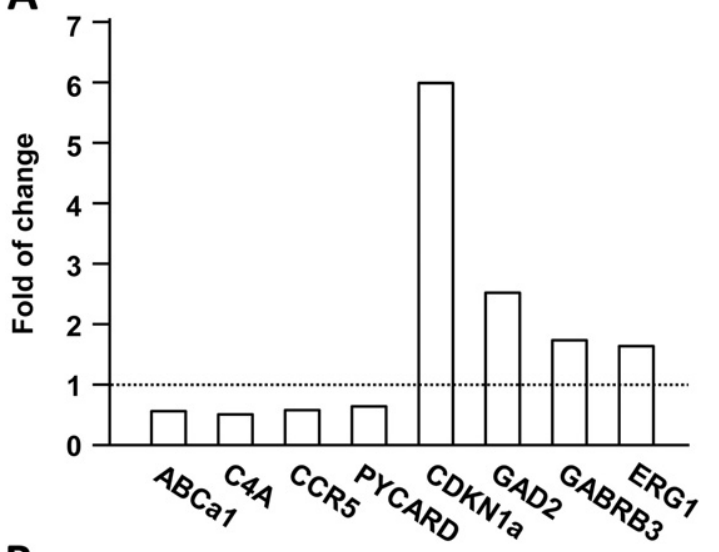

B

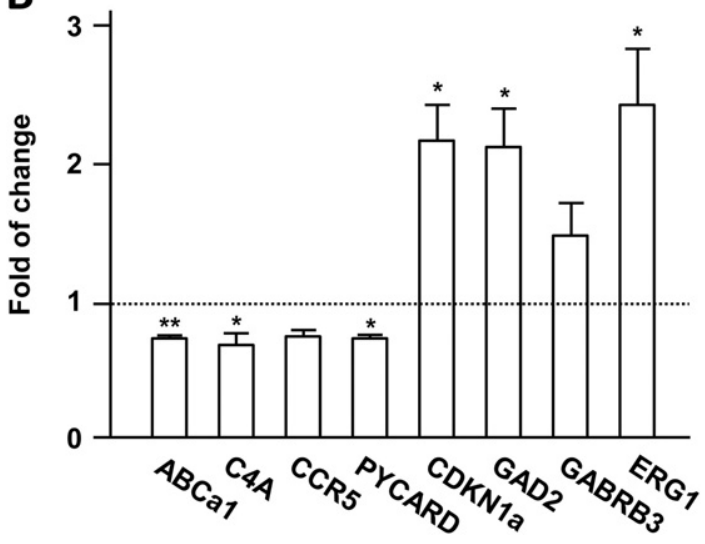

Fig. 2 - The messenger ribonucleic acid (mRNA) expression level of differently expressed genes in rat brain. (A) The values from microarray results are shown. (B) Total RNA was extracted from rat brain. Real-time polymerase chain reaction (PCR) was performed to measure the mRNA level of the genes ABCa1, C4A, CCR5, PYCARD, CDKN1a, GAD2, GABRB3 and EGR1. Values are expressed as the fold of change ( $X$ Basal against the control (DMSO treatment)). Statistical differences relative to the control (DMSO treatment) were analyzed by the student t-test: ${ }^{*} p<0.05$ and ${ }^{* *} p<0.01$ vs. control.

\subsection{GO function and KEGG enrichment analysis}

The GO functions closely related with genes of interest are shown in Table 2. A total of 10 biological functions were significantly enriched, such as regulation of primary metabolic process (GO: 0080090) and positive regulation of cellular metabolic process (GO: 0031323). The majority of the annotated genes were related to regulation of primary metabolic process. Pathway analysis is a functional analysis mapping genes to KEGG pathways. The Enrichment Score represents the significance of enrichment for each pathway. From this result, we found that 10 pathways were significantly up-regulated, while 3 pathways were significantly down-regulated by the differentially expressed genes in TCDD exposure group. Among the up-regulated pathways, Long-term potentiation (pathway ID: rno04720), Cholinergic synapse (rno04725) and Insulin secretion (rno04911) are most significant ones. Arachidonic acid metabolism (rno00590), Endocytosis (rno04144) and Serotonergic synapse (rno04726) were down-regulated by a lower significance (Fig. 3).

\section{Discussion}

Dioxins, as a kind of notorious persistent organic pollutant, exert their toxicity through a relatively long period and an accumulation process in human body, especially in nervous system. Several cohort studies implied potential adverse health effects such as cognitive deficit and high risk of neurological diseases, emerged after decades years of dioxin exposure (Yi et al., 2014; Schantz et al., 2001; Bouchard et al., 1999). Based on the plasma dioxin concentration from dioxin polluted area (Pelclova et al., 2009), we designed our exposure dose of dioxin for rat experiments. To our knowledge, this study is the first application of animals after prolonged exposure of dioxin at low concentration for the analysis of effects of dioxin on brain tissue, which could reflect more real and comprehensive effects of dioxin in brains.

Microarray data suggested that synaptic plasticity might be a vulnerable target of dioxin. The up-regulation expression of camk II and camk4 in the TCDD-treated group suggested the activated $\mathrm{Ca}^{2+}$ signal pathway by dioxin, and creb1 expression

Table 2 - The results of GO function analysis.

\begin{tabular}{llll}
\multicolumn{1}{c}{ GO.ID } & \multicolumn{1}{c}{ Term } & Fold Enrichment & $p$-Value \\
\hline GO: 0080090 & Regulation of primary metabolic process & 1.984103585 & $4.19063 \mathrm{E}-11$ \\
GO: 0031323 & Regulation of cellular metabolic process & 1.944188418 & $7.71575 \mathrm{E}-11$ \\
GO: 0019222 & Regulation of metabolic process & 1.774316373 & 1.968416287 \\
GO: 0006810 & Transport & 1.836576337 & $1.53258 \mathrm{E}-09$ \\
GO: 0060255 & Regulation of macromolecule metabolic process & 1.922079371 & $3.27817 \mathrm{E}-08$ \\
GO: 0051234 & Establishment of localization & 1.788708772 & $3.99049 \mathrm{E}-08$ \\
GO: 0048518 & Positive regulation of biological process & 1.859544993 & $1.33064 \mathrm{E}-07$ \\
GO: 0048519 & Negative regulation of biological process & 2.756768416 & $1.40202 \mathrm{E}-07$ \\
GO: 0042981 & Regulation of apoptotic process & 2.174421257 & $1.79676 \mathrm{E}-07$ \\
GO: 0009893 & Positive regulation of metabolic process & & $1.86674 \mathrm{E}-07$ \\
\hline
\end{tabular}

GO: Gene Ontology. 

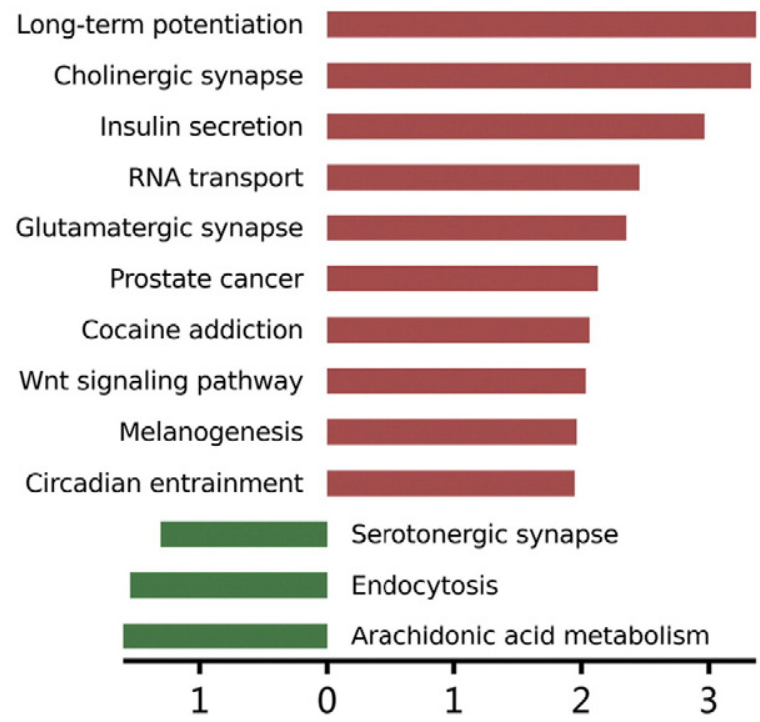

\section{Enrichment Score (- $\log 10 p$-value)}

\section{Down-regulated Up-regulated}

Fig. 3 - KEGG pathway analysis. The bar plot shows the top ten Enrichment score $(-\log 10(p$-value)) value of the significant enrichment pathway. Red and green bars represent the up- and down-regulated pathways respectively. The length of the bars stands for the significance of the enrichment. KEGG: Kyoto Encyclopedia of Genes and Genomes.

was also induced by dioxin. These molecular physiological processes have been linked to the synaptic activity such as changes in synaptic strength and the regulation of neuronal survival and death (Curtis and Finkbeiner, 1999; Xi et al., 2016; Lee et al., 2004). And another up-regulated gene, Early Growth Response 1 (EGR1), has been documented as a critical integrator and mediator of synaptic plasticity and neuronal activity in both physiological and pathological conditions (Duclot and Kabbaj, 2017). It is noted that EGR1 could regulate multiple aspects of synaptic plasticity, such as neurotransmitters metabolism, actin cytoskeleton, Long-term potentiation (LTP) maintenance, and vesicular release endocytosis (Koldamova et al., 2014; Duclot and Kabbaj, 2015; Penke et al., 2014). In fact, the intracellular calcium increases in hippocampal neurons followed by up-regulation of EGR1 (Bading et al., 1995). Furthermore, the expression of creb1 and jund in the brain was elevated by dioxin, these two transcription factors could bind their respective response elements located in the erg1 promoter (Tur et al., 2010). It is known that TCDD increases the expression of transcription factor EGR1 in the lung epithelial cells, kidney cells and hematopoietic stem cells (Martinez et al., 2004; Aida-Yasuoka et al., 2014; Casado et al., 2011; Keshava et al., 2005), but this is the first time to report that TCDD regulates erg1 expression in nervous system. Although overexpression of EGR1 in primary cultured rat hippocampal neurons caused reduction in PSD-95 protein level (Qin et al., 2015), our data showed an increase in the expression of dlg4 (a gene encoding PSD-95), which was consistent with the expression profile in the rat after chronic electroconvulsive stimulation (ECS) (Dyrvig et al., 2014), suggesting time difference of gene expression. PSD-95 is a member of the synapse-associated protein family of scaffolding molecules that control the organization, composition and function of synapses, the abnormal expression of dlg4 gene shown synaptic plasticity defect and was detected in Alzheimer's patients (Migaud et al., 1998; Leuba et al., 2008). gad2 encoding one isoform of glutamate decarboxylase, which is the rate-limiting enzyme in the synthesis of GABA, was also detected up-regulated by dioxin. gad2 knockout mice displayed impaired GABA synaptic release indicated its important role in the plasticity of central GABA synapses (Pan, 2012; Kash et al., 1997). Another GABAergic system member, gabrb3, together with gad2 has been regard as candidate gene of autism spectrum disorders (Chen et al., 2014). Autistic traits have been observed in the children after perinatal dioxin exposure (Nishijo et al., 2014), but the underlying mechanism still needs to be elucidated.

The genes (abca1, pycard, ccr5) involved in the production and of Interleukin-1 (IL-1), were down-regulated by dioxin suggested immune system dysfunction in the brain caused by dioxin. IL-1, as A pro-inflammatory cytokine, plays an important role in immune response in central nervous system (Weiss et al., 1989), and have influence on the dopaminergic and serotoninergic neurotransmission systems (Felger and Miller, 2012; Felger et al., 2013). In addition, IL-1 could also influence brain function through their effect on hippocampal neuroplasticity and neurogenesis (Yirmiya and Goshen, 2011) or via neuro-endocrine mechanisms involving the hypothalamic pituitary-adrenal axis (HPA) functioning (Goshen and Yirmiya, 2009). Dioxin has been reported to up-regulate the expression and secretion of pro-inflammatory cytokines in cultured HAPI microglial cells after acute exposure (Xu et al., 2013). Although our microarray results did not show any significant changes of the expression of genes coding pro-inflammatory cytokines in the TCDD-treated group, the down-regulation of ATP-binding membrane cassette transporter A1 (ABCA1) might also cause inflammatory response (Schmitz et al., 1999; Aiello et al., 2003). Moreover, the main role of ABCA1 is mediation of the transport of cholesterol, phospholipids and other lipophilic molecules across cellular membranes to lipid-poor High-density lipoproteins (HDL) apolipoproteins (Tang and Oram, 2009). Dysregulation of cholesterol transportation and metabolism has been proved to be associated with several neurodegenerative diseases, such as Alzheimer's disease (AD) and Huntingdon's diseases (HD) (Di Paolo and Kim, 2011; Karasinska and Hayden, 2011). PYCARD (apoptosis-associated speck-like protein containing a CARD or ASC) mediates the assembly of large signaling complexes in the inflammatory and apoptotic signaling pathways via activation of caspase. PYCARD is a key factor in the caspase 1 activation and IL-1 $\beta$ maturation (Kumar et al., 2013). Down-regulation of pycard might lead to suppression of secretion of IL-1 $\beta$ (Couturier et al., 2016). Deficiency of C-C chemokine receptor 5(CCR5) activated astrocytes and induced $A \beta$ accumulation, these processes might extend neuroinflammation and contribute to the development and the progression of AD (Hwang et al., 2016; Simard et al., 2006; Stalder et al., 2005). Suppression messenger ribonucleic acid (mRNA) level of ccr5 caused by dioxin might give some support to associate dioxin exposure to immune system dysfunction 
in brain. Furthermore, the activation of $\mathrm{Ca}^{2+}$ signal pathway and jund up-regulation caused by dioxin also predict the neuro-inflammation toxicity of dioxin (Xu et al., 2013; Sul et al., 2009; N’Diaye et al., 2006).

\section{Conclusions}

This is the first report about the microarray study to identify differentially expressed genes in rat brain after environmental related dose and long-term dioxin exposure. Several genes encoding key protein in maintaining the synaptic plasticity and participating in the neuro-inflammation have been identified to response to dioxin.

\section{Acknowledgment}

This research was supported by grants from the Natural Science Foundation of China (Nos. 21407171, 21377160, 21525730), and the Strategic Priority Research Program of the Chinese Academy of Sciences (No. XDB14030400).

\section{RE F E R E N C ES}

Aida-Yasuoka, K., Yoshioka, W., Kawaguchi, T., Ohsako, S., Tohyama, C., 2014. A mouse strain less responsive to dioxininduced prostaglandin E2 synthesis is resistant to the onset of neonatal hydronephrosis. Toxicol. Sci. 141 (2), 465-474.

Aiello, R.J., Brees, D., Francone, O.L., 2003. ABCA1-deficient mice Insights into the role of monocyte lipid efflux in HDL formation and inflammation. Arterioscler. Thromb. Vasc. Biol. 23 (6), 972-980.

Bading, H., Segal, M.M., Sucher, N.J., Dudek, H., Lipton, S.A., Greenberg, M.E., 1995. N-Methyl-D-Aspartate Receptors Are Critical for Mediating the Effects of Glutamate on Intracellular Calcium-Concentration and Immediate-Early Gene-Expression in Cultured Hippocampal-Neurons. Neuroscience 64 (3), 653-664.

Bell, D.R., Clode, S., Fan, M.Q., Fernandes, A., Foster, P.M., Jiang, T., et al., 2007. Toxicity of 2,3,7,8-tetrachlorodibenzo-p-dioxin in the developing male Wistar(Han) rat. II: Chronic dosing causes developmental delay. Toxicol. Sci. 99 (1), 224-233.

Bouchard, M.F., Oulhote, Y., Sagiv, S.K., Saint-Amour, D., Weuve, J., 2014. Polychlorinated biphenyl exposures and cognition in older U.S. adults: NHANES (1999-2002). Environ. Health Perspect. 122 (1), 73-78.

Casado, F.L., Singh, K.P., Gasiewicz, T.A., 2011. Aryl hydrocarbon receptor activation in hematopoietic stem/progenitor cells alters cell function and pathway-specific gene modulation reflecting changes in cellular trafficking and migration. Mol. Pharmacol. 80 (4), 673-682.

Chen, X., Ma, X.M., Ma, S.W., Coenraads, P.J., Zhang, C.M., Liu, J., et al., 2009. Proteomic analysis of the rat ovary following chronic low-dose exposure to 2,3,7,8-tetrachlorodibenzo-p-dioxin (TCDD). J. Toxicol. Environ. Health A 72 (11-12), 717-726.

Chen, C.H., Huang, C.C., Cheng, M.C., Chiu, Y.N., Tsai, W.C., Wu, Y.Y., et al., 2014. Genetic analysis of GABRB3 as a candidate gene of autism spectrum disorders. Mol. Autism 5, 36

Couturier, J., Stancu, I.C., Schakman, O., Pierrot, N., Huaux, F., Kienlen-Campard, P., et al., 2016. Activation of phagocytic activity in astrocytes by reduced expression of the inflammasome component ASC and its implication in a mouse model of Alzheimer disease. J. Neuroinflammation 13 (1), 20.

Curtis, J., Finkbeiner, S., 1999. Sending signals from the synapse to the nucleus: possible roles for CaMK, Ras/ERK, and SAPK pathways in the regulation of synaptic plasticity and neuronal growth. J. Neurosci. Res. 58 (1), 88-95.

Di Paolo, G., Kim, T.W., 2011. Linking lipids to Alzheimer's disease: cholesterol and beyond (vol 12, pg 284, 2011). Nat. Rev. Neurosci. 12 (8).

Duclot, F., Kabbaj, M., 2015. The estrous cycle surpasses sex differences in regulating the transcriptome in the rat medial prefrontal cortex and reveals an underlying role of early growth response 1. Genome Biol. 16.

Duclot, F., Kabbaj, M., 2017. The Role of Early Growth Response 1 (EGR1) in Brain Plasticity and Neuropsychiatric Disorders. Front. Behav. Neurosci. 11, 35.

Dyrvig, M., Christiansen, S.H., Woldbye, D.P., Lichota, J., 2014. Temporal gene expression profile after acute electroconvulsive stimulation in the rat. Gene 539 (1), 8-14.

Felger, J.C., Miller, A.H., 2012. Cytokine effects on the basal ganglia and dopamine function: The subcortical source of inflammatory malaise. Front. Neuroendocrinol. 33 (3), 315-327.

Felger, J.C., Mun, J., Kimmel, H.L., Nye, J.A., Drake, D.F., Hernandez, C.R., et al., 2013. Chronic Interferon-alpha Decreases Dopamine 2 Receptor Binding and Striatal Dopamine Release in Association with Anhedonia-Like Behavior in Nonhuman Primates. Neuropsychopharmacology 38 (11), 2179-2187.

Goshen, I., Yirmiya, R., 2009. Interleukin-1 (IL-1): a central regulator of stress responses. Front. Neuroendocrinol. 30 (1), $30-45$.

Huang, D.W., Sherman, B.T., Lempicki, R.A., 2009. Systematic and integrative analysis of large gene lists using DAVID bioinformatics resources. Nat. Protoc. 4 (1), 44-57.

Hwang, C.J., Park, M.H., Hwang, J.Y., Kim, J.H., Yun, N.Y., Oh, S.Y., et al., 2016. CCR5 deficiency accelerates lipopolysaccharideinduced astrogliosis, amyloid-beta deposit and impaired memory function. Oncotarget 7 (11), 11984-11999.

Kakeyama, M., Endo, T., Zhang, Y., Miyazaki, W., Tohyama, C., 2014. Disruption of paired-associate learning in rat offspring perinatally exposed to dioxins. Arch. Toxicol. 88 (3), 789-798.

Karasinska, J.M., Hayden, M.R., 2011. Cholesterol metabolism in Huntington disease. Nat. Rev. Neurol. 7 (10), 561-572.

Kash, S.F., Johnson, R.S., Tecott, L.H., Noebels, J.L., Mayfield, R.D., Hanahan, D., et al., 1997. Epilepsy in mice deficient in the 65$\mathrm{kDa}$ isoform of glutamic acid decarboxylase. Proc. Natl. Acad. Sci. U. S. A. 94 (25), 14060-14065.

Keshava, C., Whipkey, D., Weston, A., 2005. Transcriptional signatures of environmentally relevant exposures in normal human mammary epithelial cells: benzo[a]pyrene. Cancer Lett. 221 (2), 201-211.

Koldamova, R., Schug, J., Lefterova, M., Cronican, A.A., Fitz, N.F., Davenport, F.A., et al., 2014. Genome-wide approaches reveal EGR1-controlled regulatory networks associated with neurodegeneration. Neurobiol. Dis. 63, 107-114.

Kumar, M., Roe, K., Orillo, B., Muruve, D.A., Nerurkar, V.R., Gale Jr., M., et al., 2013. Inflammasome adaptor protein Apoptosisassociated speck-like protein containing CARD (ASC) is critical for the immune response and survival in west Nile virus encephalitis. J. Virol. 87 (7), 3655-3667.

Lee, S.J., Campomanes, C.R., Sikat, P.T., Greenfield, A.T., Allen, P.B., McEwen, B.S., 2004. Estrogen induces phosphorylation of cyclic AMP response element binding ( $\mathrm{PCREB}$ ) in primary hippocampal cells in a time-dependent manner. Neuroscience 124 (3), 549-560.

Leuba, G., Walzer, C., Vernay, A., Camal, B., Kraftsik, R., Piotton, F., et al., 2008. Postsynaptic density protein PSD-95 expression in Alzheimer's disease and okadaic acid induced neuritic retraction. Neurobiol. Dis. 30 (3), 408-419. 
Martinez, J.M., Baek, S.J., Mays, D.M., Tithof, P.K., Eling, T.E., Walker, N.J., 2004. EGR1 is a novel target for AhR agonists in human lung epithelial cells. Toxicol. Sci. 82 (2), 429-435.

Migaud, M., Charlesworth, P., Dempster, M., Webster, L.C., Watabe, A.M., Makhinson, M., et al., 1998. Enhanced long-term potentiation and impaired learning in mice with mutant postsynaptic density-95 protein. Nature 396 (6710), 433-439.

Mitsuhashi, T., Yonemoto, J., Sone, H., Kosuge, Y., Kosaki, K., Takahashi, T., 2010. In utero exposure to dioxin causes neocortical dysgenesis through the actions of p27Kip1. Proc. Natl. Acad. Sci. U. S. A. 107 (37), 16331-16335.

Nayyar, T., Zawia, N.H., Hood, D.B., 2002. Transplacental effects of 2,3,7,8-tetrachlorodibenzo-p-dioxin on the temporal modulation of Sp1 DNA binding in the developing cerebral cortex and cerebellum. Exp. Toxicol. Pathol. 53 (6), 461-468.

N’Diaye, M., Le Ferrec, E., Lagadic-Gossmann, D., Corre, S., Gilot, D., Lecureur, V., et al., 2006. Aryl hydrocarbon receptor- and calcium-dependent induction of the chemokine CCL1 by the environmental contaminant benzo[a]pyrene. J. Biol. Chem. 281 (29), 19906-19915.

Nguyen, A.T., Nishijo, M., Hori, E., Nguyen, N.M., Pham, T.T., Fukunaga, K., et al., 2013. Influence of Maternal Exposure to 2,3,7,8-Tetrachlorodibenzo-p-dioxin on Socioemotional Behaviors in Offspring Rats. Environ. Health Insights 7, 1-14.

Nishijo, M., Pham, T.T., Nguyen, A.T., Tran, N.N., Nakagawa, H., Hoang, L.V., et al., 2014. 2,3,7,8-Tetrachlorodibenzo-p-dioxin in breast milk increases autistic traits of 3-year-old children in Vietnam. Mol. Psychiatry 19 (11), 1220-1226.

Pan, Z.Z., 2012. Transcriptional control of Gad2. Transcription 3 (2), 68-72.

Pelclova, D., Fenclova, Z., Urban, P., Ridzon, P., Preiss, J., Kupka, K., et al., 2009. Chronic health impairment due to 2,3,7,8tetrachloro-dibenzo-p-dioxin exposure. Neuroendocrinol. Lett. 30 (Suppl. 1), 219-224.

Penke, Z., Morice, E., Veyrac, A., Gros, A., Chagneau, C., LeBlanc, P., et al., 2014. Zif268/Egr1 gain of function facilitates hippocampal synaptic plasticity and long-term spatial recognition memory. Philos. Trans. R. Soc. Lond. Ser. B Biol. Sci. 369 (1633), 20130159.

Qin, X., Jiang, Y., Tse, Y.C., Wang, Y., Wong, T.P., Paudel, H.K., 2015. Early Growth Response 1 (Egr-1) Regulates N-Methyl-d-aspartate Receptor (NMDAR)-dependent Transcription of PSD-95 and alpha-Amino-3-hydroxy-5-methyl-4-isoxazole Propionic Acid Receptor (AMPAR) Trafficking in Hippocampal Primary Neurons. J. Biol. Chem. 290 (49), 29603-29616.

Schantz, S.L., Gasior, D.M., Polverejan, E., McCaffrey, R.J., Sweeney, A.M., Humphrey, H.E., et al., 2001. Impairments of memory and learning in older adults exposed to polychlorinated biphenyls via consumption of Great Lakes fish. Environ. Health Perspect. 109 (6), 605-611.

Schmitz, G., Kaminski, W.E., Porsch-Ozcurumez, M., Klucken, J., Orso, E., Bodzioch, M., et al., 1999. ATP-binding cassette transporter A1 (ABCA1) in macrophages: a dual function in inflammation and lipid metabolism? Pathobiology 67 (5-6), 236-240.
Simard, A.R., Soulet, D., Gowing, G., Julien, J.P., Rivest, S., 2006. Bone marrow-derived microglia play a critical role in restricting senile plaque formation in Alzheimer's disease. Neuron 49 (4), 489-502.

Stalder, A.K., Ermini, F., Bondolfi, L., Krenger, W., Burbach, G.J., Deller, T., et al., 2005. Invasion of hematopoietic cells into the brain of amyloid precursor protein transgenic mice. J. Neurosci. 25 (48), 11125-11132.

Sul, D., Kim, H.S., Cho, E.K., Lee, M., Kim, H.S., Jung, W.W., et al., 2009. 2,3,7,8-TCDD neurotoxicity in neuroblastoma cells is caused by increased oxidative stress, intracellular calcium levels, and tau phosphorylation. Toxicology 255 (1-2), 65-71.

Tang, C.R., Oram, J.F., 2009. The cell cholesterol exporter ABCA1 as a protector from cardiovascular disease and diabetes. Biochim. Biophys. Acta Mol. Cell Biol. Lipids 1791 (7), 563-572.

Tur, G., Georgieva, E.I., Gagete, A., Lopez-Rodas, G., Rodriguez, J.L., Franco, L., 2010. Factor binding and chromatin modification in the promoter of murine Egr1 gene upon induction. Cell. Mol. Life Sci. 67 (23), 4065-4077.

Weiss, B., 2000. Vulnerability to pesticide neurotoxicity is a lifetime issue. Neurotoxicology 21 (1-2), 67-73.

Weiss, J.M., Sundar, S.K., Becker, K.J., Cierpial, M.A., 1989. Behavioral and neural influences on cellular immune responses: effects of stress and interleukin-1. J. Clin. Psychiatry 50, 43-53 (Suppl. discussion 54-45).

Williamson, M.A., Gasiewicz, T.A., Opanashuk, L.A., 2005. Aryl hydrocarbon receptor expression and activity in cerebellar granule neuroblasts: implications for development and dioxin neurotoxicity. Toxicol. Sci. 83 (2), 340-348.

Wu, J., Mao, X., Cai, T., Luo, J., Wei, L., 2006. KOBAS server: a webbased platform for automated annotation and pathway identification. Nucleic Acids Res. 34 (Web Server issue), W720-724.

Xi, Y.D., Zhang, D.D., Ding, J., Yu, H.L., Yuan, L.H., Ma, W.W., et al., 2016. Genistein Inhibits Abeta25-35-Induced Synaptic Toxicity and Regulates CaMKII/CREB Pathway in SH-SY5Y Cells. Cell. Mol. Neurobiol. 36 (7), 1151-1159.

Xie, H.Q., Xu, H.-M., Fu, H.-L., Hu, Q., Tian, W.-J., Pei, X.-H., et al., 2013. AhR-Mediated Effects of Dioxin on Neuronal Acetylcholinesterase Expression in Vitro. Environ. Health Perspect. 121 (5), 613-618.

Xu, G., Li, Y., Yoshimoto, K., Chen, G., Wan, C., Iwata, T., et al., 2013. 2,3,7,8-Tetrachlorodibenzo-p-dioxin-induced inflammatory activation is mediated by intracellular free calcium in microglial cells. Toxicology 308, 158-167.

Yi, S.W., Hong, J.S., Ohrr, H., Yi, J.J., 2014. Agent Orange exposure and disease prevalence in Korean Vietnam veterans: the Korean veterans health study. Environ. Res. 133, 56-65.

Yirmiya, R., Goshen, I., 2011. Immune modulation of learning, memory, neural plasticity and neurogenesis. Brain Behav. Immun. 25 (2), 181-213. 